This item was submitted to Loughborough's Research Repository by the author.

Items in Figshare are protected by copyright, with all rights reserved, unless otherwise indicated.

\title{
Assessment of surface hardening effects from shot peening on a Ni-based alloy using electron backscatter diffraction techniques
}

\section{PLEASE CITE THE PUBLISHED VERSION}

http://dx.doi.org/10.1016/j.actamat.2011.04.025

\section{PUBLISHER}

Elsevier Ltd / @ Acta Materialia Inc.

\section{VERSION}

SMUR (Submitted Manuscript Under Review)

\section{LICENCE}

CC BY-NC-ND 4.0

\section{REPOSITORY RECORD}

Child, Daniel, G.D. West, and Rachel C. Thomson. 2014. "Assessment of Surface Hardening Effects from Shot Peening on a Ni-based Alloy Using Electron Backscatter Diffraction Techniques". figshare. https://hdl.handle.net/2134/15341. 
This item was submitted to Loughborough's Institutional Repository (https://dspace.lboro.ac.uk/) by the author and is made available under the following Creative Commons Licence conditions.

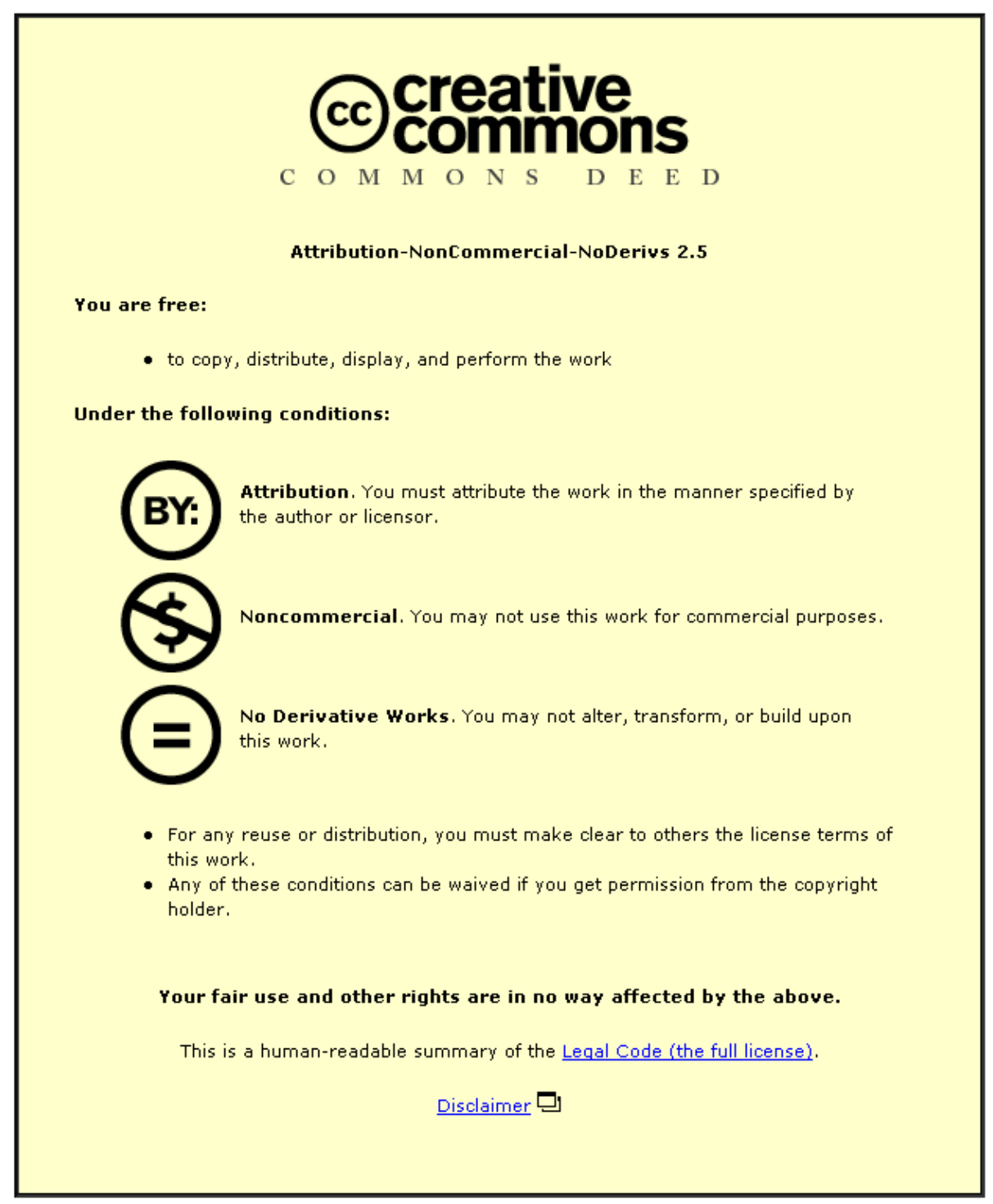

For the full text of this licence, please go to: http://creativecommons.org/licenses/by-nc-nd/2.5/ 


\title{
Title: Assessment of Surface Hardening Effects from Shot Peening on a Ni-Based Alloy using Electron Backscatter Diffraction Techniques
}

\section{D.J. Child ${ }^{a}$,}

e-mail:d.child@lboro.ac.uk

G.D. West ${ }^{a}$,

e-mail: g.d.west@lboro.ac.uk

R.C. Thomson ${ }^{a, *}$ (corresponding author)

e-mail: r.c.thomson@lboro.ac.uk

Telephone: +44(0)1509 223155

${ }^{a}$ Department of Materials, Loughborough University, Loughborough, Leicestershire, United Kingdom, LE11 $3 T U$.

\begin{abstract}
An electron backscatter diffraction (EBSD)-based tool is described to assess the depth of strain hardening effects of shot peening treatments applied to the nickel-based superalloy, Udimet $\odot$ alloy $720 \mathrm{Li}$. The method consists of a statistical analysis of a number of data points from each grain scanned based on the grain orientation spread and their relative position from the shot peened edge. The output is a quantitative measure of the depth of strain hardening effects. The tool is used at various shot peening intensities to demonstrate the ability to distinguish between these changes, using a range of intensities from 4-10 Almen. An increase in shot peening intensity is observed to increased the depth of strain hardening effects in the alloy. A comparison with residual stress measurements using $\mathrm{X}$-ray diffraction for the same material shows that the strain hardened depth determined by EBSD extends to approximately half the distance of the residual stress present due to shot peening. A comparison is also made with predicted profiles from the Peenstress ${ }^{\mathrm{SM}}$ model and subsequent microhardness testing. A positive correlation is observed between strained hardened depth and surface roughness of the peened samples. In each case, the increases in surface roughness and strain hardened depth diminish toward the upper end of the shot peening intensity range studied for this alloy.
\end{abstract}

\section{Keywords}

Electron backscatter diffraction (EBSD), Orientation, Work hardening modelling, Nibased superalloys, Shot Peening 


\section{Introduction}

Jet turbine engines used in modern civil aviation rely heavily on the development of high temperature nickel based alloys to gain improvements in performance and efficiency. Nickel based alloys are widely used for turbine components due to their high temperature fatigue and creep resistance. In addition, they display good resistance to corrosion and oxidation under severe operating conditions. Due to the combination of harsh corrosive environments and highly stressed parts, the requirement for good fatigue crack resistance is of the utmost importance.

To improve fatigue crack resistance, shot peening has been widely used. Shot peening is a process whereby many hard particles (typically steel or glass beads), known as 'shot', are directed towards the intended surface. The impact indentations of the shot induce local plastic deformation at the surface, increasing the dislocation population to impede potential crack growth, and inducing a compressive residual stress field as a result of the recovery of underlying material [1-3].

Numerous attempts have been made to model the residual stress effects of shot peening, most notably since the early 1980s. Initial proposals by Guechichi [4] in the mid-1980s were improved by Khabou et al. [5] towards the end of the decade and revised again by Fathallah et al. [6] in 1996. Recent model predictions for residual stress profiles have shown good agreement with experimental data and software packages that are available such as Peenstress ${ }^{\text {SM }}[7]$.

Experimentally, hardness testing has been used to assess residual stresses within a microstructure introduced by shot peening [2, 8-10], although x-ray diffraction techniques are now more widely employed [11-13]. Despite numerous measurements 
of residual stress to assess the effects of shot peening, a recent study by Guechichi and Castex [14] provides evidence that strain hardening and not residual stress is the primary contributor to fatigue resistance. Such claims are enhanced if residual stress relaxation is considered, as shown by Evans et al. [3], who demonstrate that one cycle of high temperature isothermal fatigue is enough to reduce residual stress levels in a nickel-based superalloy by more than 50 per cent. More recent studies [15-17], have highlighted the ability of electron backscatter diffraction (EBSD) data to assess strain hardening levels in alloys, building on use of the focussed ion beam to look more carefully at surface and sub-surface features [18]. Wilkinson et al. [19] go further in quantifying strain, using cross-correlation measurements of small shifts in EBSD patterns, to a sensitivity of $10^{-4}$. Deformation assessments have also been achieved with measures of an 'image quality' parameter. Image quality describes the quality of an EBSD pattern by measuring the perfection of the crystal lattice in the diffracting volume. More highly strained microstructures are prone to increased dislocation interference resulting in reduced image quality during data collection. Image quality provides a reasonable estimation of microstructural strain as shown by Yoda et al. [15], but the parameter is dependent on the material, absolute grain orientation and sample preparation of the diffracting volume. The same paper by Yoda et al., also demonstrates an improved ability to measure strain differences between grains using an average misorientation per grain parameter. The average misorientation per grain parameter measures orientation within a grain on a kernel-by-kernel basis, averaging the mismatch between adjacent kernels and assigning this as the average misorientation for that grain. Another parameter, kernel misorientation, provides similar information, but keeps the data on a point-by-point basis rather than averaging for the grain, and has been used to 
assess irradiation-induced strain hardening [16]. However, to date, an EBSD technique to assess the strain hardening effects of shot peening has not been presented.

The EBSD grain misorientation parameters discussed above provide a more reliable method of assessing grain damage due to induced strain hardening, compared to hardness, which includes some contribution from residual stresses [20]. EBSD provides Eüler orientation angle data on every point scanned in a pre-defined area, to identify the orientation of a grain in three dimensions. Grains defined within an alloy consist of many kernels (from tens to thousands) of data depending on grain size and scan resolution. Individual grains within regions experiencing zero strain will largely display a constant orientation. In regions subject to strain hardening, local orientation differences are observed within deformed grains. Thus, deformed grain areas can be distinguished from unaffected grain areas in components subjected to a surface-only compressive strain, as in shot peening.

A method is described in this paper to define the depth to which the strain hardening effects of shot peening penetrates into the microstructure of a nickel-based superalloy using an EBSD tool. The method will be used at various shot peen intensities to demonstrate the ability of the tool to distinguish between these changes. A comparison with residual stress measurements using XRD for the same material presented by Evans et al. [3] is made, and data are compared with predicted results from the Peenstress ${ }^{\text {SM }}$ model and subsequent microhardness testing.

\section{Experimental Procedure}

\subsection{Sample Condition and Data Collection}


A schematic diagram of the stages up to and including EBSD data collection are shown in Figure 1. Prior to shot peening, samples of alloy 720Li were cut with a high precision Struers Accutom-5 cutting machine to the size of $20 \times 15 \times 2 \mathrm{~mm}$. One of the faces measuring $20 \times 15 \mathrm{~mm}$ was prepared on five such samples to a finish of $1 \mu \mathrm{m}$, using a series of diamond polishing wheels and solutions on an automated polishing machine. The five samples were shot peened with $110 \mathrm{H}$ steel shot, at $200 \%$ coverage, at five different intensities, as shown in Figure 1(a). The shot intensities ranged from 4 to 10 Almen, as defined by the curvature of an Almen test strip exposed to the same shot as the samples. When the Almen strip deforms to a predefined curvature depth relating to a specific intensity, it was known that the shot peening was complete to the correct degree. Specifically, the intensities used were: 4-6 A, 5-7 A, 6-8 A, 7-9 A, 8-10 A. After shot peening, the samples were cross-sectioned using the Struers Accutom-5 saw at low feed, in order not to impart any edge deformation, and to enable analysis of the surface peening effects, as shown in Figure 1(b). The sample cross-sections were prepared to a finish suitable for use of electron backscatter diffraction (EBSD) analysis. EBSD preparation consisted of polishing to a $1 \mu \mathrm{m}$ finish followed by 20 minutes of treatment with $0.04 \mu \mathrm{m}$ grain size colloidal silica.

[File: Fig1]

Figure 1. Preparation of samples for electron backscatter diffraction analysis at a shot peened sample edge showing: (a) original sample dimensions, shot peened on the top face; (b) sectioned sample exposing the cross-section subsequently prepared for EBSD; (c) location of EBSD scan area relative to shot peened sample edge.

EBSD data were collected using an EDAX Hikari EBSD camera, situated within an FEI Nova 600 Nanolab Dual-Beam field emission gun scanning electron microscope 
(FEGSEM)/focussed ion beam (FIB) system. Data collection at a rate of 258 frames per second was performed over a scan area of $200 \times 250 \mu \mathrm{m}$ from the shot peened sample edge, as shown in Figure 1(c). A step size of $0.4 \mu \mathrm{m}$ was used during scans, resulting in the acquisition of 312,500 data points across the area of interest, and an approximate scan time of 20 minutes. Two such scans were performed for each of the shot peen intensities.

\subsection{Data Processing and Analysis}

The EBSD data were analysed using TSL OIM Analysis 5.31 software. The software allows users to define grains by criteria such as rotation angle and size. In this study, grains were defined by a grain angle of 1 degree and a size of 10 data points. Thus, if two points have an orientation 1 degree or more they are identified as two separate grains, but only if they are in a group of 10 or more similar points (separated by less than 1 degree). Cleaning operations were applied to the scans to remove rogue points. Data were then exported into an ASCII-type format for use in a spreadsheet program. The data extracted were on a grain-by-grain basis, specifying the grain orientation spread (GOS) for each grain in the scan, with it's $\mathrm{x}$ and y co-ordinates. The $\mathrm{x}$ and $\mathrm{y}$ coordinates for a grain were taken as the centre of mass for the grain shape. A spreadsheet was used first to sort the data based on the y co-ordinate beginning with the grain furthest from the shot peened edge, then to calculate an average of GOS of the preceding 150 grains (starting with the $151^{\text {st }}$ grain). The average and standard deviation of the baseline GOS in the alloy was taken from the first $100 \mu \mathrm{m}$ of grains. The sum of these two values provided the threshold above which any GOS would be deemed as significant, and indicative of shot peening deformation effects. The point at which the average of the preceding 150 grains was greater than the sum of average and standard 
deviation of GOS defined the beginning of the 'zone of deformation'. The depth of the zone of deformation was calculated by subtracting the y-co-ordinate of the first grain to be deemed as within the zone of deformation from the maximum y co-ordinate of the scan area. The graph shown in Figure 2 is a schematic view of a typical line of best fit from the ASCII data plotted as GOS against y co-ordinate. Figure 2 shows the definition of the deformation zone as calculated by deviation from the baseline GOS.

[File: Fig2]

Figure 2. Schematic plot of grain orientation spread versus y co-ordinate for a number of hypothetical grains, enabling definition of the zone of deformation in a surfaceaffected alloy.

Data can also be displayed more visually using OIM to show maps of the scanned area, colour-coded based on the GOS assigned to each grain. These were used as a more intuitive method to visually compare the various shot peen intensities, in addition to the statistical analysis detailed above. The EBSD data also allows use of the image quality (IQ) parameter to highlight grain boundaries, which can be incorporated into the maps as a greyscale underlay.

\subsection{Microhardness Testing}

Microhardness tests were performed to accompany the GOS data. Microhardness tests were performed using a Mitutoyo HM-124 hardness testing machine. A $0.05 \mathrm{~kg}$ load was applied at a speed of $33 \mu \mathrm{ms}^{-1}$, into the surfaces prepared as described above, to a colloidal silica finish suitable for EBSD. Fifteen indents were made from the sample edge towards the centre, spaced approximately $35 \mu \mathrm{m}$ apart.

\subsection{Surface Profilometry}


Surface profilometry measurement were also performed on each of the surfaces at the different shot peening intensities. Measurements were performed using a Zygo Newview 5000 white light interferometer. Five areas of 500 x $700 \mu \mathrm{m}$ was analysed for each intensity, with the resulting data being used to calculate an average value of $S_{a}$ in each case. $S_{a}$ describes the surface area roughness, as opposed to $R_{a}$, which measures only one particular profile. The equation used to calculate $S_{a}$ is given below as Equation 1 [21]:

$S_{\varangle}=\frac{1}{M N} \sum_{j=1}^{W} \sum_{i=1}^{M}|z|\left(x_{i j} y_{j}\right)$

where $\mathrm{M}$ is the number of columns in the surface and $\mathrm{N}$ is the number of rows in the surface, with $\mathrm{x}, \mathrm{y}$ and $\mathrm{z}$ the co-ordinates of each data point.

\section{Results}

\subsection{Model Validation with Microhardness Testing and Surface Profilometry}

\section{Measurements}

Peenstress ${ }^{\mathrm{SM}}$ is a residual stress modelling program utilised by Metal Improvement Company, the details of which are included in [7]. The software enables a profile of residual stress in the alloy to be predicted for each of the shot peen intensities, based on a number of factors such as material, material heat treatment, part geometry and shot characteristics. The model relies on a number of assumptions [7]:

- Shot impingement is perpendicular to the surface;

- The shot media is spherical and equal to the specified diameter;

- The impact velocity of the media is constant; 
- The hardness of the media is at least equal to that of the material.

The predicted values of residual stress are shown in Table 1, with these data shown graphically in Figure 3, where the stress curve prediction for each intensity has a varying plateau of peak compressive stress which declines to zero stress some way into the alloy (shown later in Figure 13).

\begin{tabular}{ccc}
\hline $\begin{array}{c}\text { Shot peen intensity / } \\
\text { Almen }\end{array}$ & $\begin{array}{c}\text { Predicted depth of peak } \\
\text { stress / } \boldsymbol{\mu m}\end{array}$ & $\begin{array}{c}\text { Predicted depth to zero } \\
\text { stress / } \boldsymbol{\mu m}\end{array}$ \\
\hline $4-6$ & 43 & 140 \\
\hline $5-7$ & 52 & 160 \\
\hline $6-8$ & 62 & 180 \\
\hline $7-9$ & 71 & 210 \\
\hline $8-10$ & 81 & 240 \\
\hline
\end{tabular}

Table 1. Predicted residual stress profiles by Peenstress ${ }^{\mathrm{SM}}$, at five different shot peen intensities for nickel-based alloy $720 \mathrm{Li}$.

[File: Fig3]

Figure 3. Graph plotting predicted 'peak to zero' stress range versus shot peen intensity for a nickel-based alloy. Predictions are modelled based on nickel-based alloy $720 \mathrm{Li}$ composition and heat treatment, using $110 \mathrm{H}$ steel shot at $200 \%$ coverage.

Microhardness measurements were taken from the edges of each of the shot peened samples as a method of validating the Peenstress ${ }^{\mathrm{SM}}$ model predictions of residual stress. Figure 4 shows a hardness profile plot for each shot peening intensity beginning close to the shot peened edge and ending between 400 and $500 \mu \mathrm{m}$ away from the edge. The results displayed show an average of two hardness profiles for each shot peen intensity. Table 2 shows the measured depths to which hardness is deemed to be affected by shot peening based on twice the depth to which it takes the hardness to drop by 50 per cent 
of its decrease from peak to baseline values. The data shown in Table 2 are plotted in Figure 5.

[File: Fig4]

Figure 4. Graph showing Vickers hardness versus distance from sample edge for five samples of various shot peen intensities applied to nickel-based alloy 720Li. Each line represents an average of two profiles taken from each shot peening intensity.

\begin{tabular}{cc}
\hline Shot peen intensity / Almen & Hardness affected zone / $\boldsymbol{\mu m}$ \\
\hline $4-6$ & 96 \\
\hline $5-7$ & 110 \\
\hline $6-8$ & 140 \\
\hline $7-9$ & 206 \\
\hline $8-10$ & 247 \\
\hline
\end{tabular}

Table 2. Measured hardness affected zone at five different shot peen intensities for nickel-based alloy 720Li, measured using a threshold method.

[File: Fig5]

Figure 5. Graph showing the measured hardness affected zone at five different shot peen intensities for nickel-based alloy $720 \mathrm{Li}$, measured using a threshold method.

Surface roughness measurements were taken of the surfaces at all shot peening intensities, to assess whether this parameter relates to observations recorded with EBSD. Figure 6 shows three-dimensional surface reconstructions of a selected area, for each shot peening intensity. Table 3 provides quantification of surface roughness using $S_{a}$ values, which are visualised in graphical form in Figure 7.

[File: Fig6] COLOUR 
Figure 6. Three-dimensional reconstructions by white light interferometry on five different shot peen intensities: (a) 4-6 A; (b) 5-7 A; (c) 6-8 A; (d) 7-9 A; (e) 8-10 A, applied to nickel-based alloy $720 \mathrm{Li}$.

\begin{tabular}{cc}
\hline Shot peen intensity / Almen & Surface roughness $\left(\mathbf{S}_{\mathbf{a}}\right) / \boldsymbol{\mu m}$ \\
\hline $4-6$ & 0.77 \\
\hline $5-7$ & 1.27 \\
\hline $6-8$ & 1.51 \\
\hline $7-9$ & 1.81 \\
\hline $8-10$ & 1.85 \\
\hline
\end{tabular}

Table 3. Average surface roughness quantification of five surfaces $(500 \times 700 \mu \mathrm{m}$ in area) subject to various shot peening intensity applied to nickel-based alloy $720 \mathrm{Li}$, using a white light interferometry technique.

[File: Fig7]

Figure 7. Graphical representation of the average surface roughness quantification of five surfaces (500 x $700 \mu \mathrm{m}$ in area) subject to various shot peening intensity applied to nickel-based alloy $720 \mathrm{Li}$, using a white light interferometry technique.

\subsection{Microstructural Examination and EBSD Analysis}

Figure 8 shows ion beam induced secondary electron images of a shot peened sample cross section, taken using an FEI Nova 600 Nanolab Dual-Beam FEGSEM/FIB system using a $30 \mathrm{pA}$ aperture. The samples pictured in Figure 8 are exposed to the lowest and highest shot peening intensities of 4-6 A and 8-10 A respectively, which were protected during ion beam clean-up with a deposited Pt layer.

[File: Fig8] 
Figure 8. Ion beam induced secondary electron images of a nickel-based alloy cross section with a shot peened surface exposed to (a) 4-6 A; (b) 8-10 A intensity, with $110 \mathrm{H}$ steel shot at $200 \%$ coverage.

EBSD scanning of each of the samples (designated by the shot peen intensity to which they were exposed) produced data to create the GOS maps in colour, with a greyscale IQ map underlay. One set of maps for all five samples is shown in Figure 9. Using the method described in the experimental section, the zone of deformation was calculated for each shot peen intensity. The value was an average of data from two different scan areas at each intensity, and is shown in Table 4, and displayed in Figure 10.

\section{[File: Fig9] COLOUR}

Figure 9. Maps of grain orientation spread (colour) and image quality (greyscale) for five shot peen intensities: (a) 4-6 A; (b) 5-7 A; (c) 6-8 A; (d) 7-9 A; (e) 8-10 A, applied to nickel-based alloy $720 \mathrm{Li}$, showing the effects of surface deformation at the exposed sample edge (top).

\begin{tabular}{cc}
\hline Shot peen intensity / Almen & Measured zone of deformation / $\boldsymbol{\mu m}$ \\
\hline $4-6$ & 47 \\
\hline $5-7$ & 54 \\
\hline $6-8$ & 71 \\
\hline $7-9$ & 106 \\
\hline $8-10$ & 103 \\
\hline
\end{tabular}

Table 4. Measured zone of deformation depths at five different shot peen intensities for nickel-based alloy $720 \mathrm{Li}$, measured using the grain orientation threshold method described.

[File: Fig10]

Figure 10. Graph showing the measured deformation zone using the EBSD tool for five samples of various shot peen intensities applied to nickel-based alloy 720Li. Each point represents an average of two measurements taken from each shot peening intensity. 


\section{Discussion}

\subsection{Model Validation with Microhardness Testing and Surface Profilometry Measures}

The predictions of residual stress induced by shot peening predicted by Peenstress ${ }^{\text {SM }}$ shown in Table 1 and Figure 3, suggest a linear increase in affected depth as shot peening intensity increases.

The use of hardness measurements through the profiles of the specimens is a commonly used method of assessing residual stress within a microstructure. Figure 4 shows hardness plotted on an absolute scale for each shot peening intensity. Figure 5 shows more clearly the hardness affected zones for each shot peening intensity and shows a general pattern of decrease in surface hardness, but more specifically sets apart the two highest intensities (7-9A and 8-10 A) as maintaining high hardness levels further into the alloy. If hardness results are compared with Peenstress ${ }^{\mathrm{SM}}$ simulations in Figure 12 , it is observed that there is excellent agreement at higher shot intensities. At 6-8 A and below there is slightly less agreement, although the general correlation is good. The results would suggest that hardness measures are indeed indicative of the residual stresses present in the samples, but the effects of pure strain hardening at the surface are more difficult to resolve. The EBSD misorientation tool can be used to allow strain hardening effects to be determined.

Another observation from hardness testing is the near-surface absolute hardness. Nearsurface hardness is observed to be highest at the highest shot peening intensities, excluding perhaps an anomalous 5-7A intensity. Increased surface hardness provides 
clear evidence of the greater extent of work hardening in the more intensely shot peened samples.

Use of the white light interferometry to assess surface roughness provides another comparison for the predicted residual stress as a result of shot peening. Figure 6 shows the visual differences between the different shot peening intensities, which are quantified in Table 3 and Figure 7. Figure 7 highlights the levelling of the shot peening influence at the highest intensities. Whereas the model predictions show a largely linear relationship, with perhaps an increase in gradient at higher intensities, it appears that the surface profilometry technique shows decreasing plateau effect at higher intensities, with a slight decrease at the highest intensity. This decreasing gradient at higher intensities is also a feature of the hardness results in Figure 5, although less pronounced. A possible explanation for the levelling effect at higher intensities is that the microstructure has reached a saturation point, whereby any additional shot impacts fail to further impart any residual stress into the alloy, but instead merely attempts to deform an increasingly work hardened surface. By using the EBSD grain orientation tool, the effects of strain hardening for each intensity can be assessed.

\subsection{Microstructural Examination and EBSD Analysis}

Observation of the shot peened cross sections in Figure 8 shows the extent of strain hardening at the sample surfaces. The sample shown in Figure 8(a) is of the lowest intensity of 4-6 A, but still displays the effects of strain hardening with high dislocation densities present near the shot peened surface. Figure 8(b) shows a higher magnification image of the 8-10 A shot peened intensity sample, which displays a much greater degree of dislocations, extending deeper into the alloy. Figure 8(b) also shows a 
near surface region with an unrecognisable grain structure. Ortiz et al. [22] have observed a similar effect in a single phase face-centred cubic nickel-based alloy, using TEM analysis to determine that this region consists of very fine grains of the order of 10-20 nm in size, containing few dislocations and twins and hence very low lattice strains.

Figure 9 shows the GOS maps produced using the EBSD misorientation tool at the different shot peening intensities. It is immediately observable that the strain hardened region extends progressively deeper into the alloy with increasing shot peening intensity. When this depth is quantified using the method described in the experimental section, as shown in Table 4 and Figure 10, it can be seen that the strain hardened region does indeed extend increasingly deeper into the alloy with increasing intensity. However, at intensities above 7-9 A, there is a slight decrease, suggesting a levelling of the affected depth. Figure 11 compares the results from the EBSD misorientation tool with those from the surface profilometry. In both cases, it can be seen that there is a similar levelling of each measurement parameter. This would suggest that a peening saturation level does indeed exist in the alloy. The hardness results also suggest a decreasing gradient at higher intensities, and are established as a reliable method of residual stress measurement. It is noted that Zinn and Scholtes [23], have previously suggested that there are limitations in defining residual stress depth by Almen intensity. They argued that data scatter are high when assuming linear increases in residual stress zones with shot peening intensity based on Almen measures.

[File: Fig11]

Figure 11. Comparison of a measured deformation zone from the EBSD tool with surface roughness measurements from a white light interferometer (both fitted with 
logarithmic lines of best fit), for the same surfaces at different shot intensities induced by shot peening on nickel-based alloy $720 \mathrm{Li}$.

It is also possible to consider the contribution of strain hardening as a proportion of the total surface effects induced by shot peening. Figure 12 compares the model predictions with the hardness results and the EBSD misorientation tool. Figure 12 shows the relative contributions of residual stress, as measured by hardness values, and strain hardening in the alloy, as measured by the EBSD tool, studied at different shot peeening intensities. It can be determined that strain hardening contributes an average of approximately half to the total internal alloy strain measured by hardness testing. This corresponds well to examples from other studies [8, 24, 25], which also suggest that strain hardening extends to approximately half the depth of residual stresses.

[File: Fig12]

Figure 12. Comparison of predicted values of shot peening affected zone from Computer Simulation with results from hardness testing and results from the EBSD misorientation tool in nickel-based alloy $720 \mathrm{Li}$ subjected to shot peening at various intensities.

A previous study by Evans et al. [3] has observed the effects of residual stress relaxation in alloy $720 \mathrm{Li}$ under high temperature isothermal fatigue. Included in their analysis is a study of residual stresses in a 6-8 A sample (with identical shot size and coverage) using x-ray diffraction techniques described in the introduction, without relaxation. The results from the Evans et al. study are included in Figure 13 to compare the model predictions, microhardness data and depths determined by the EBSD misorientation tool. It should be noted that the results from the EBSD misorientation tool do not adhere to either y-axis, but are scaled accordingly for comparison. 
[File: Fig13]

Figure 13. Comparison of measured values from [3], predicted values of the shot peening affected zone [7], results from hardness testing and results from the EBSD misorientation tool in a nickel-based alloy subjected to shot peening at a 6-8 Almen intensity with $110 \mathrm{H}$ steel shot at 200 per cent coverage.

Figure 13 shows good agreement between the residual stress results from Evans et al. and the model predictions, in terms of the affected depth, but with some discrepancy over the magnitude of peak residual stress. The EBSD misorientation tool developed in this paper represents strain hardening effects, which are shown to extend approximately 50 per cent of the depth of the residual stresses. The microhardness results show values in between the residual stress, and those of the EBSD misorientation tool, although they are closer to the depths determined using the EBSD misorientation tool. It is well known that hardness values are highly dependent on the level of strain hardening in a material [25], but are also affected, to some extent, by the presence of residual stresses [20]. Therefore it is unsurprising that the microhardness values lie somewhere between the EBSD misorientation tool representing strain hardening, and the XRD values representing residual stress.

\section{Conclusions}

The validity of an EBSD-based tool to measure the effect of shot peening on work hardening at different shot peening intensities has been demonstrated. The method consists of a statistical analysis of a number of data points from each grain scanned 
based on the grain orientation spread and their relative position from the shot peened edge. The output is a quantitative measure of the depth of work hardening effects.

Use of the well-established method of hardness testing to assess internal alloy residual stress shows a clear influence of shot peening intensity on affected depth. Higher shot peening intensities show evidence for residual stress further into the alloy and an increased near-surface hardness due to increasing work hardening effects. There is some suggestion that hardness values begin to level out at higher intensities.

White light interferometry provides a measure of surface roughness for each shot peened sample, showing a linear increase in roughness up to the higher intensities which also show a levelling out of the measurement parameter.

Use of the EBSD misorientation tool developed in this paper to assess strain hardening shows an increase in the measured strain hardened affected depth as shot peening intensity increases. Results from the developed tool corroborate well with surface roughness results, showing a replication of the levelling effects seen in the other test methods at the highest intensities. The levelling effect also seen through different test methods suggest that shot peening reaches a saturation level in the alloy studied, whereby an increase in shot peening intensity has increasingly less effect on the affected depth of the alloy as dislocation density saturates. This saturation at high intensities is not predicted by computer simulation, which is perhaps a limitation of the assumptions in the model formulation.

An EBSD tool based on grain orientation has been developed and assessed in this research. It has been demonstrated that it can be used to assess strain hardening effects as a result of shot peening, which are the primary contributor to fatigue resistance. 
Residual stress, on the other hand, can be determined using diffraction techniques which agree well with theoretical predictions. It has been shown that the strain hardening determined by EBSD extends to a distance of approximately half that of the initial residual stress as a result of shot peening.

\section{Acknowledgements}

We would like to thank J. Leggett, G. Gibson and D.R. Rickerby from Rolls-Royce plc., Derby, and N. Sheward from Metal Improvement Company for their valuable input into this work.

\section{References}

[1] Kobayashi M, Matsui T, Murakami Y. Int.J.Fatigue 1998;20:351.

[2] Azar V, Hashemi B, Rezaee Yazdi M. Surface and Coatings Technology 2010;204:3546.

[3] Evans A, Kim S, Shackleton J, Bruno G, Preuss M, Withers PJ. Int.J.Fatigue 2005;27:1530.

[4] Guechichi H, Castex L, Frelat J, Inglebert G. Residual Stresses in Science and Technology 1987:449.

[5] Khabou MT, Castex L, Inglebert G. European Journal of Mechanics 1989;A/Solid:537.

[6] Fathallah R, Inglebert G, Castex L. International Conference on Shot Peening-6 1996:464.

[7] Diepart CP. Materials Science Forum - ASM Heat Treatment and Surface Engineering 2 1994;163-165:457.

[8] Harada Y, Mori K. J.Mater.Process.Technol. 2005;162-163:498.

[9] Lee WB, Cho KT, Kim KH, Moon KI, Lee Y. Materials Science and Engineering: A 2010;527:5852. 
[10] Widmark M, Melander A. Int.J.Fatigue 1999;21:309.

[11] Torres MAS, Voorwald HJC. Int.J.Fatigue 2002;24:877.

[12] Wang S, Li Y, Yao M, Wang R. J.Mater.Process.Technol. 1998;73:64.

[13] Guagliano M. J.Mater.Process.Technol. 2001;110:277.

[14] Guechichi H, Castex L. J.Mater.Process.Technol. 2006;172:381.

[15] Yoda R, Yokomaku T, Tsuji N. Mater Charact 2010;61:913.

[16] Wu X, Pan X, Stubbins JF. J.Nucl.Mater. 2007;361:228.

[17] Kamaya M, Wilkinson AJ, Titchmarsh JM. Acta Materialia 2006;54:539.

[18] Okolo B, Pérez-Willard F, Hawecker J, Gerthsen D, Wanner A.

J.Mater.Process.Technol. 2007;183:160.

[19] Wilkinson AJ, Meaden G, Dingley DJ. Superlattices and Microstructures 2009;45:285.

[20] Tosha, K. 2nd Asia-Pacific Forum on Precision Surface Finishing and Deburring Technology:48.

[21] Quinsat Y, Sabourin L, Lartigue C. J.Mater.Process.Technol. 2008;195:135.

[22] Ortiz AL, Tian JW, Villegas JC, Shaw LL, Liaw PK. Acta Materialia 2008;56:413.

[23] Zinn, W, Schulz, J, Kopp, R, Scholtes, B. ICSP8:161.

[24] Rotundo F, Korsunsky AM. Procedia Engineering 2009;1:221.

[25] Fetullazade E, Akyildiz HK, Saritas S. Mater Des 2010;31:2025. 


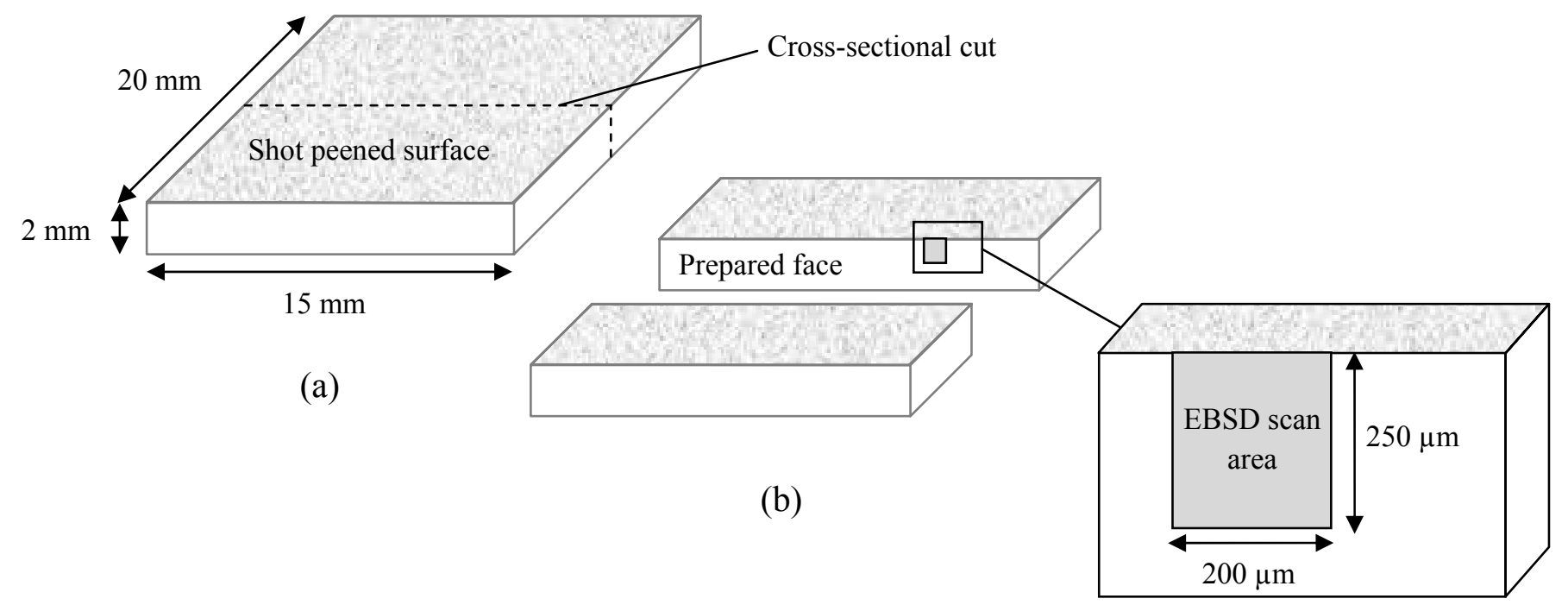

(c) 


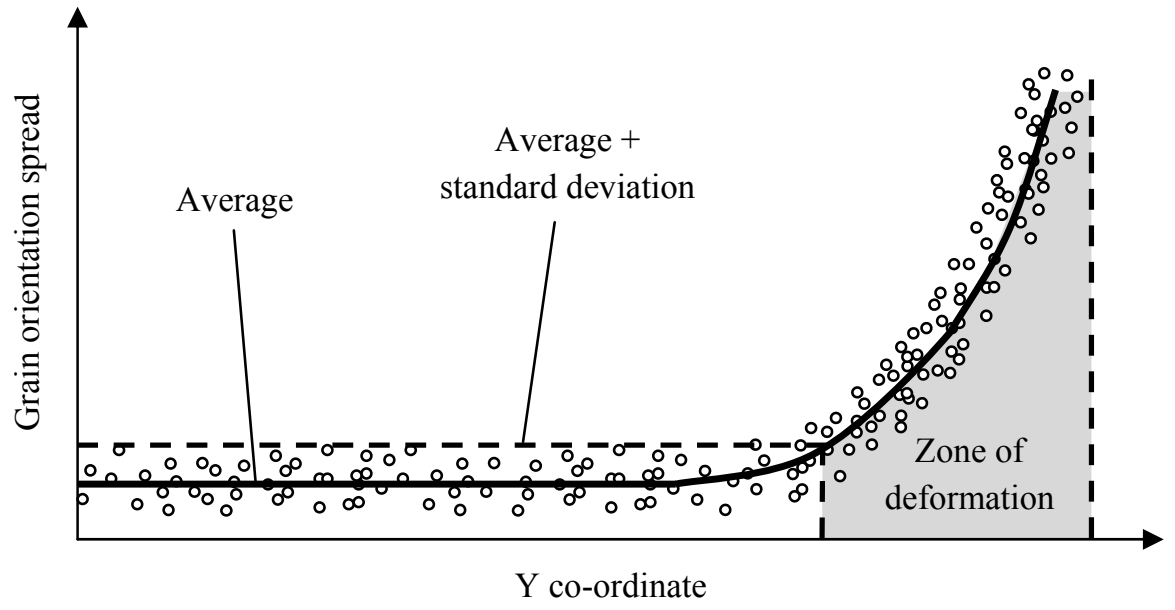




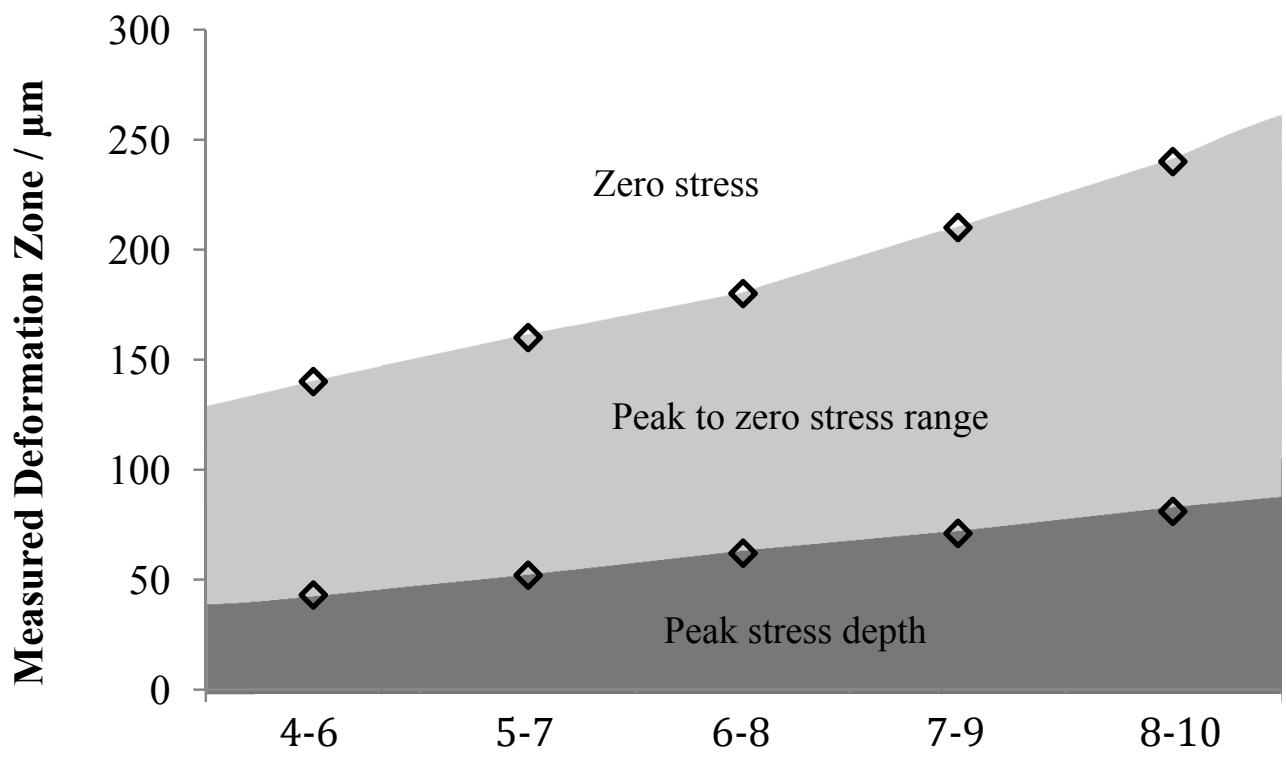

Shot Intensity / Almen 


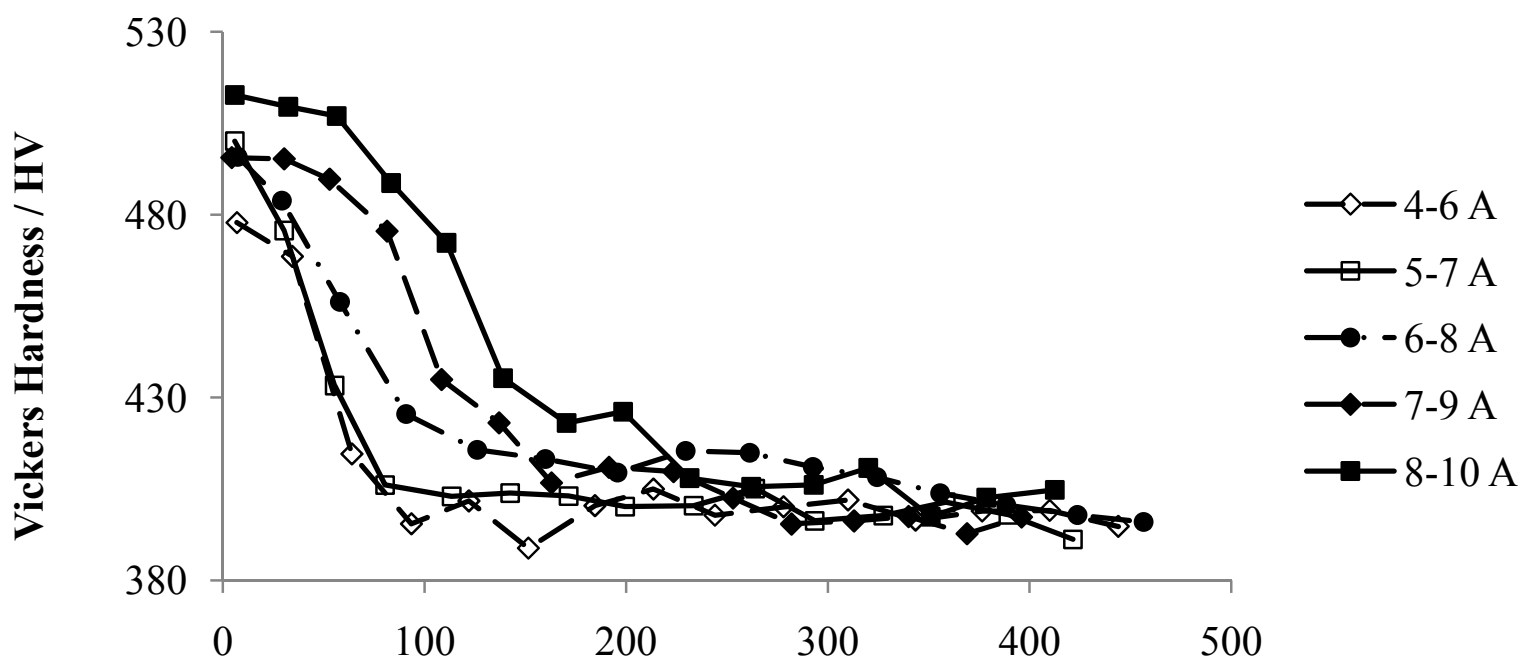

Distance from edge / $\mu \mathrm{m}$ 


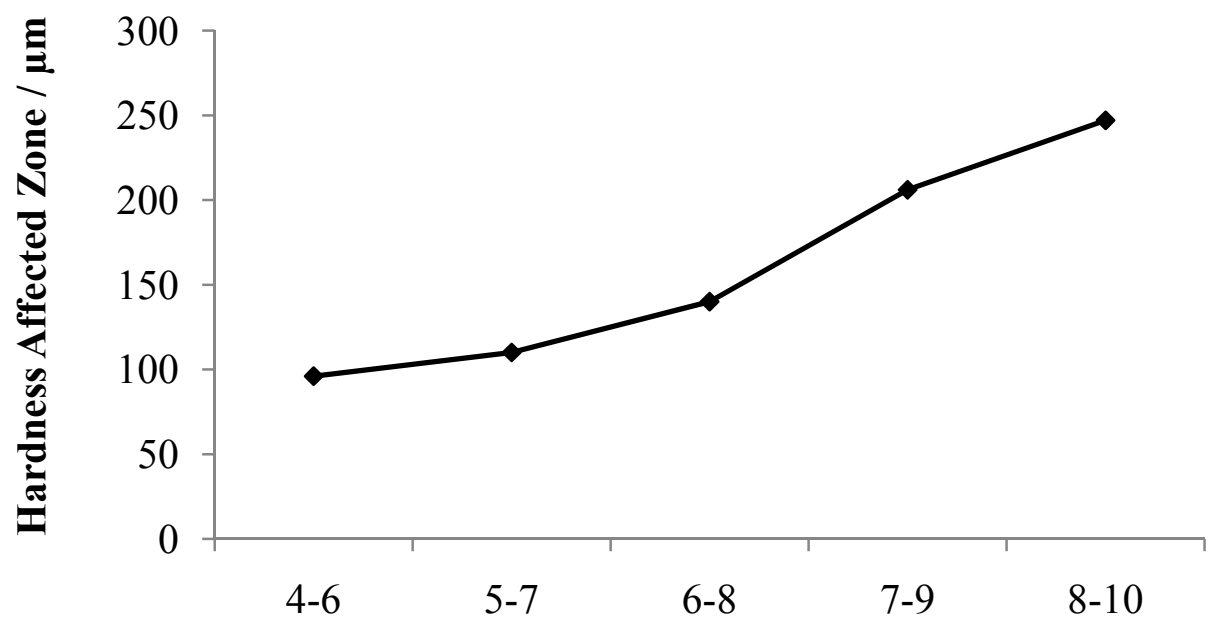

Shot Intensity / Almen 


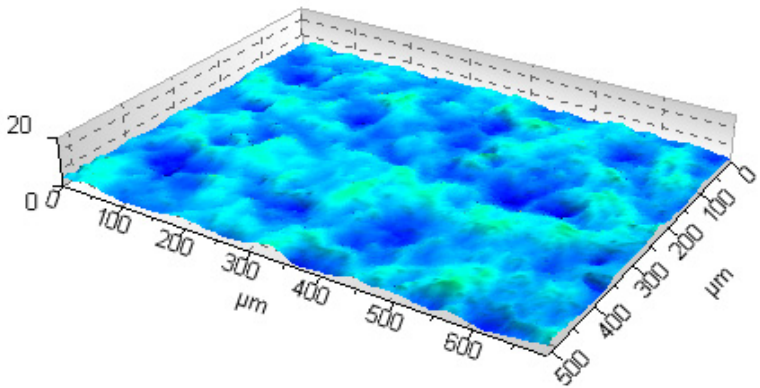

(a)

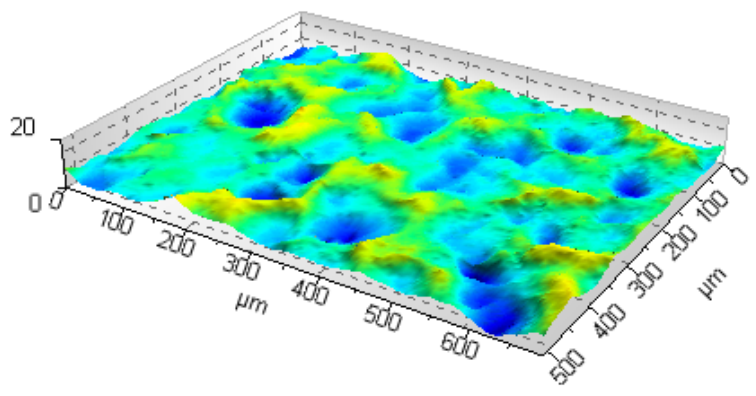

(c)

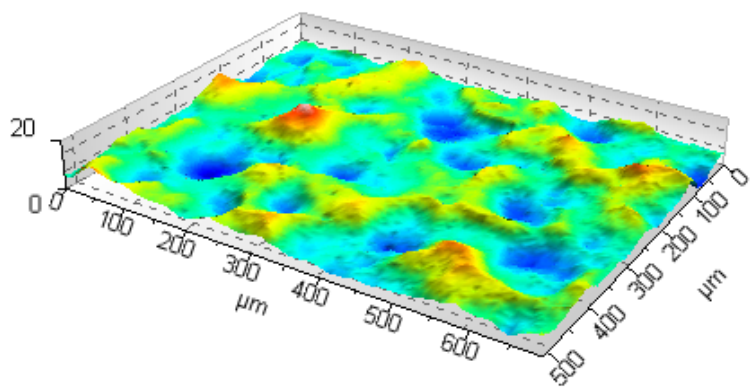

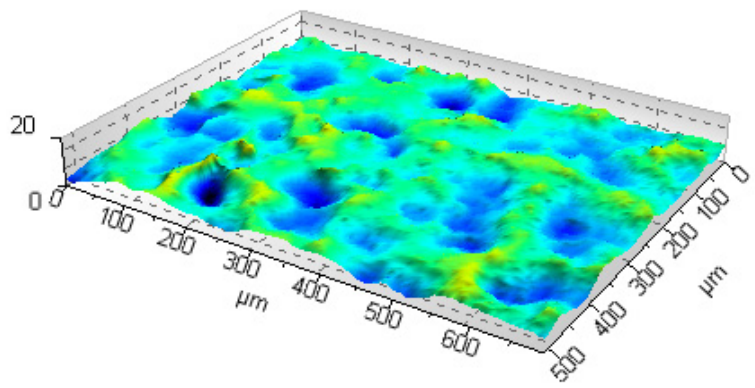

(b)

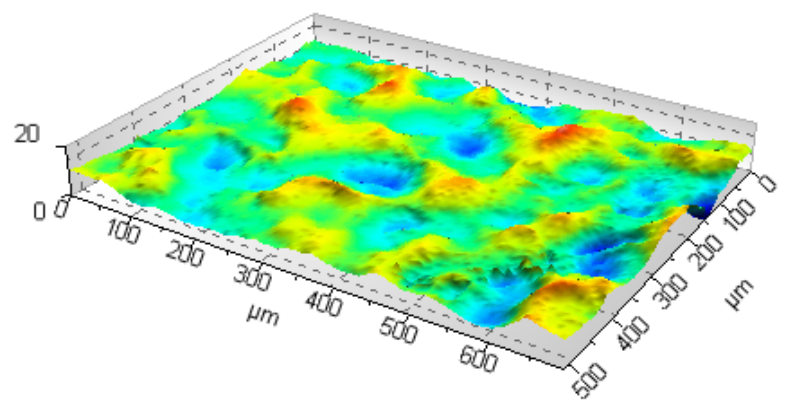

(d)

(e) 


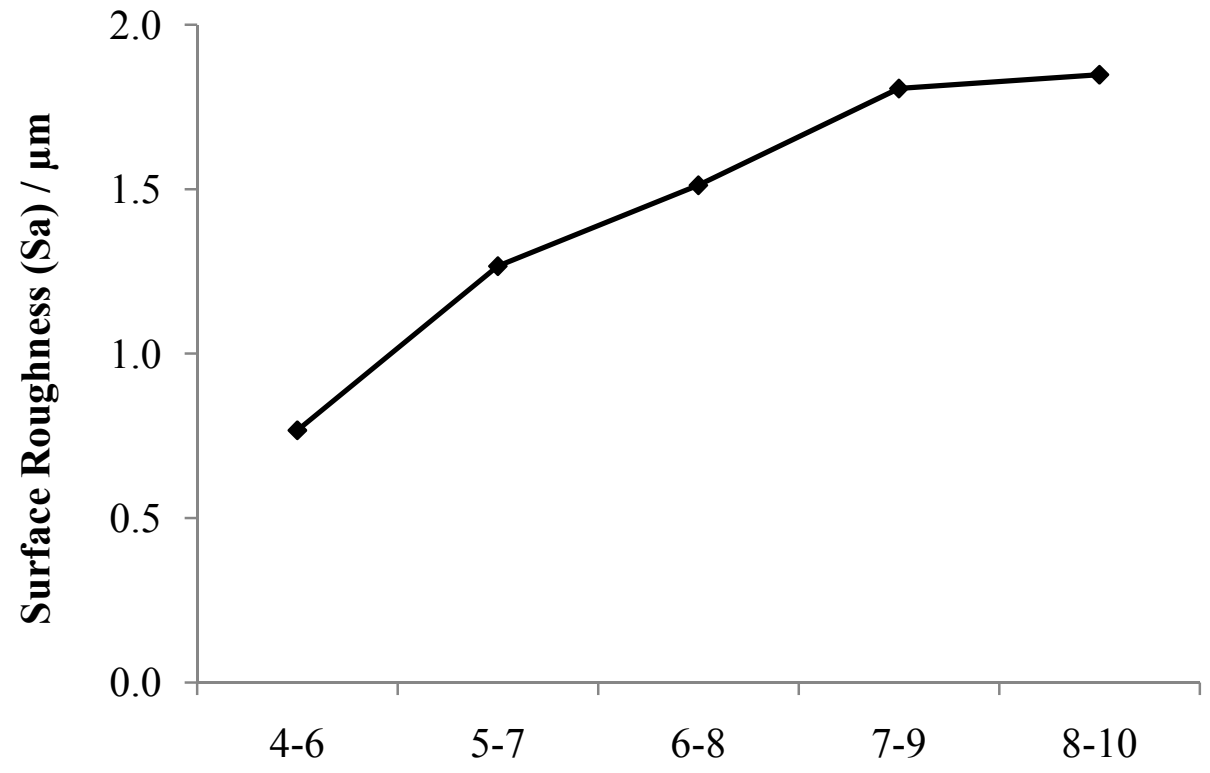

Shot Intensity / Almen 
Protective Pt layer

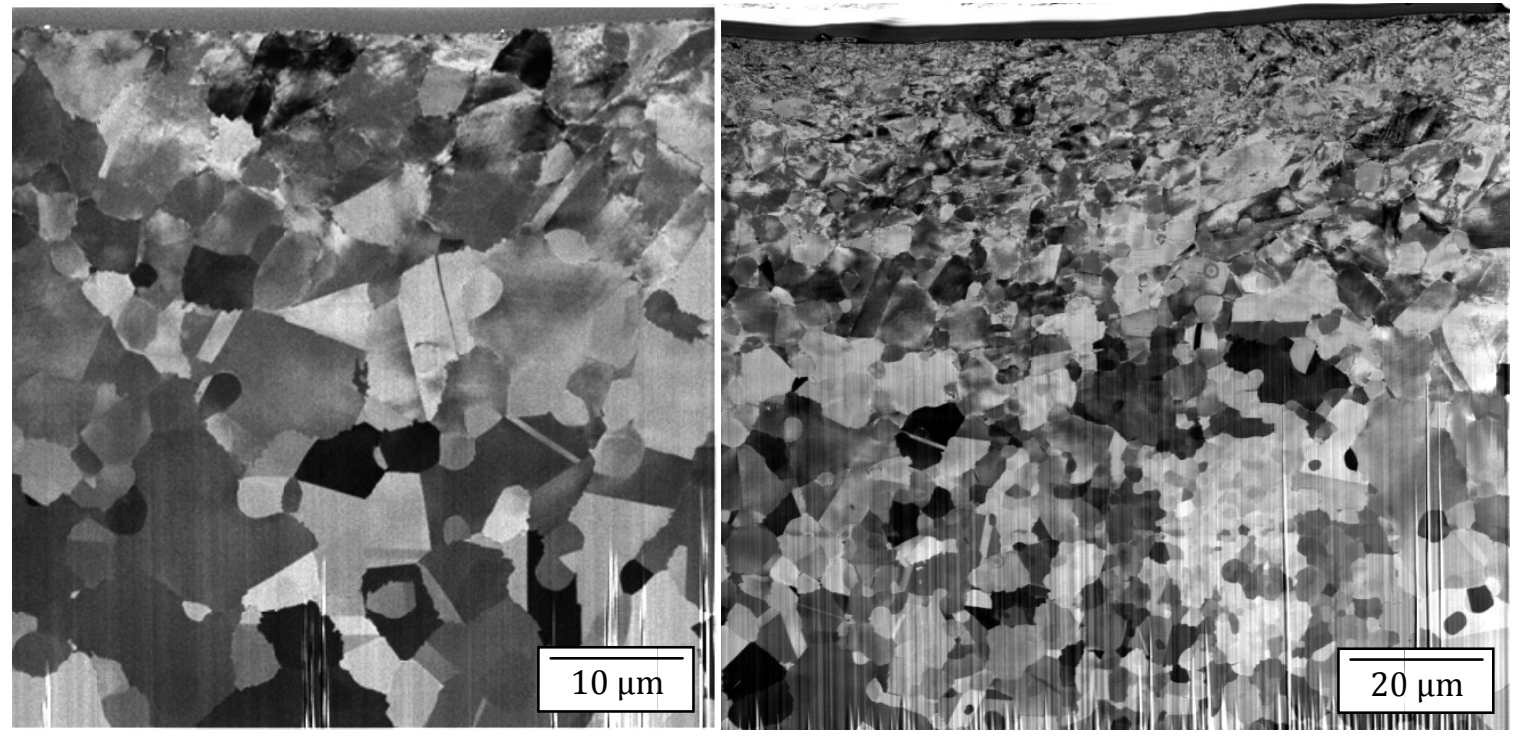

Surface

(a)

(b) 


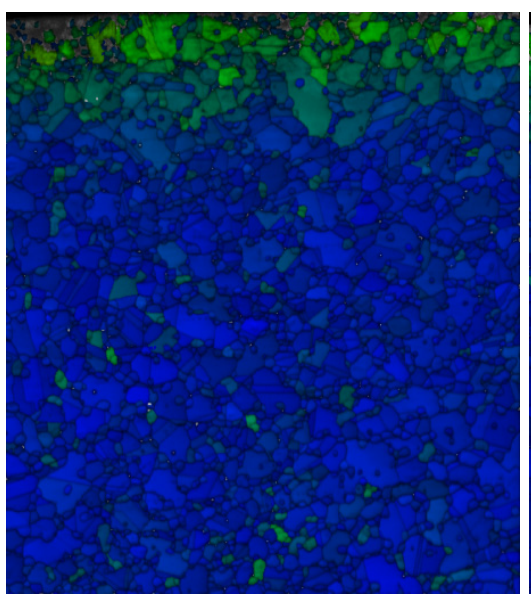

(a)

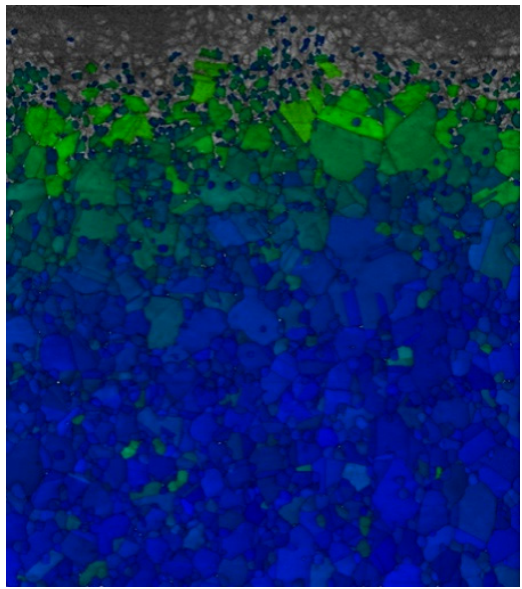

(d)

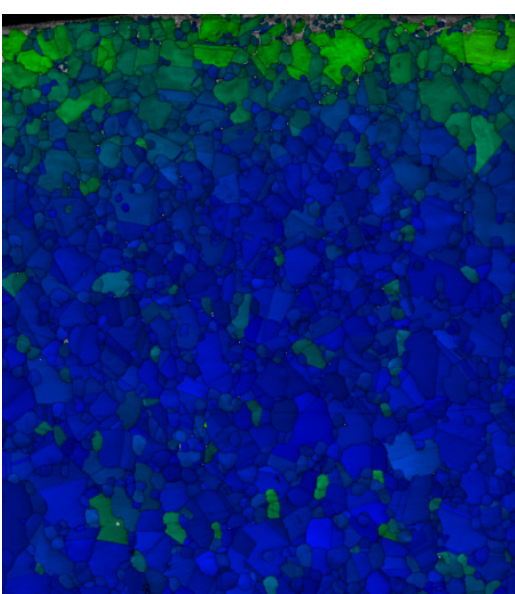

(b)

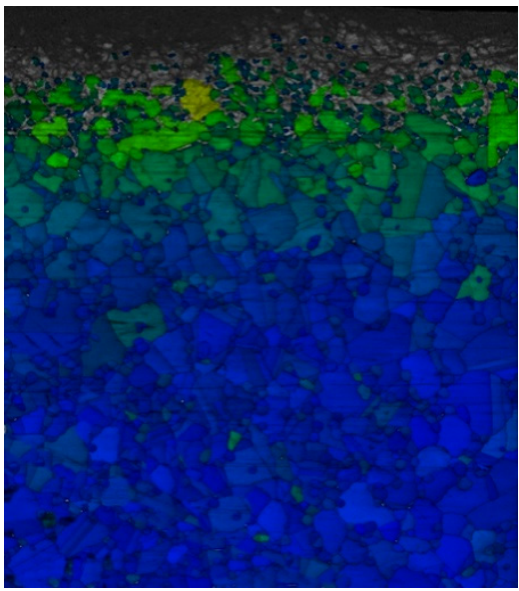

(e)

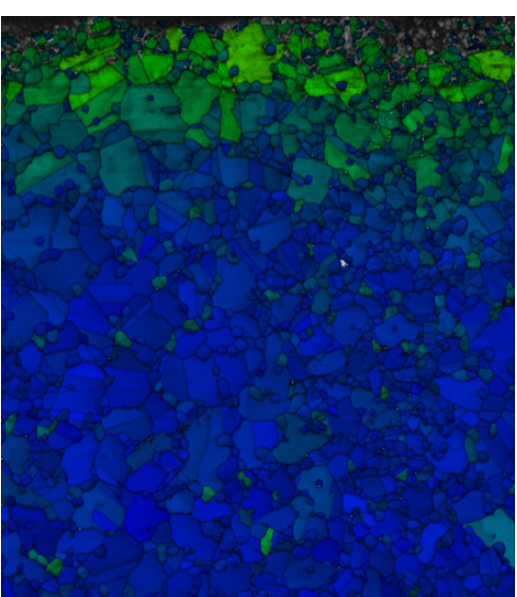

(c)

Color Coded Map Type: Grain Orientation Spread

Total

Partition

ए $\frac{\text { Min }}{0} \frac{\text { Max }}{10} \frac{\text { Fraction }}{0.942} \frac{\text { Fraction }}{0.942}$

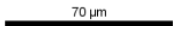




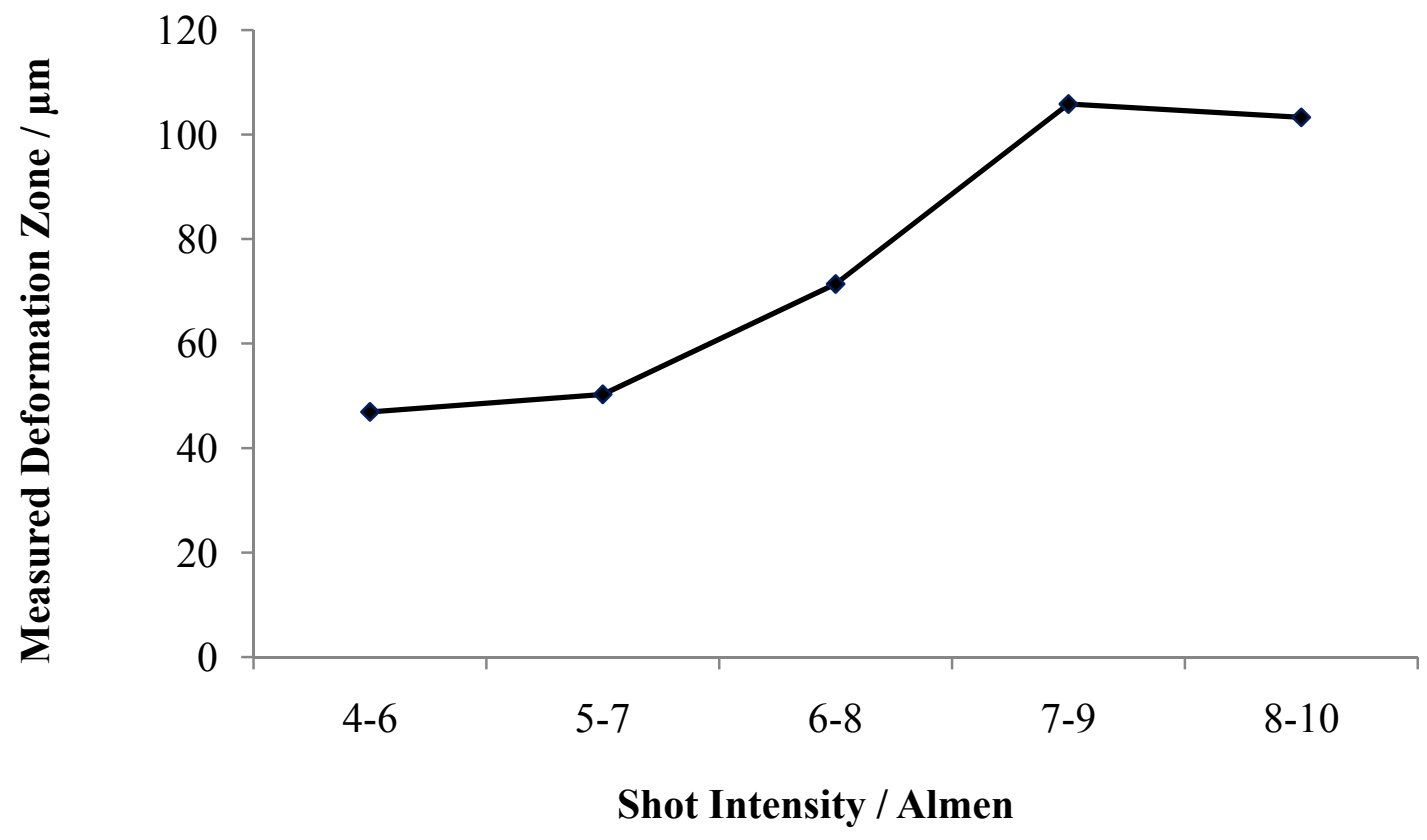




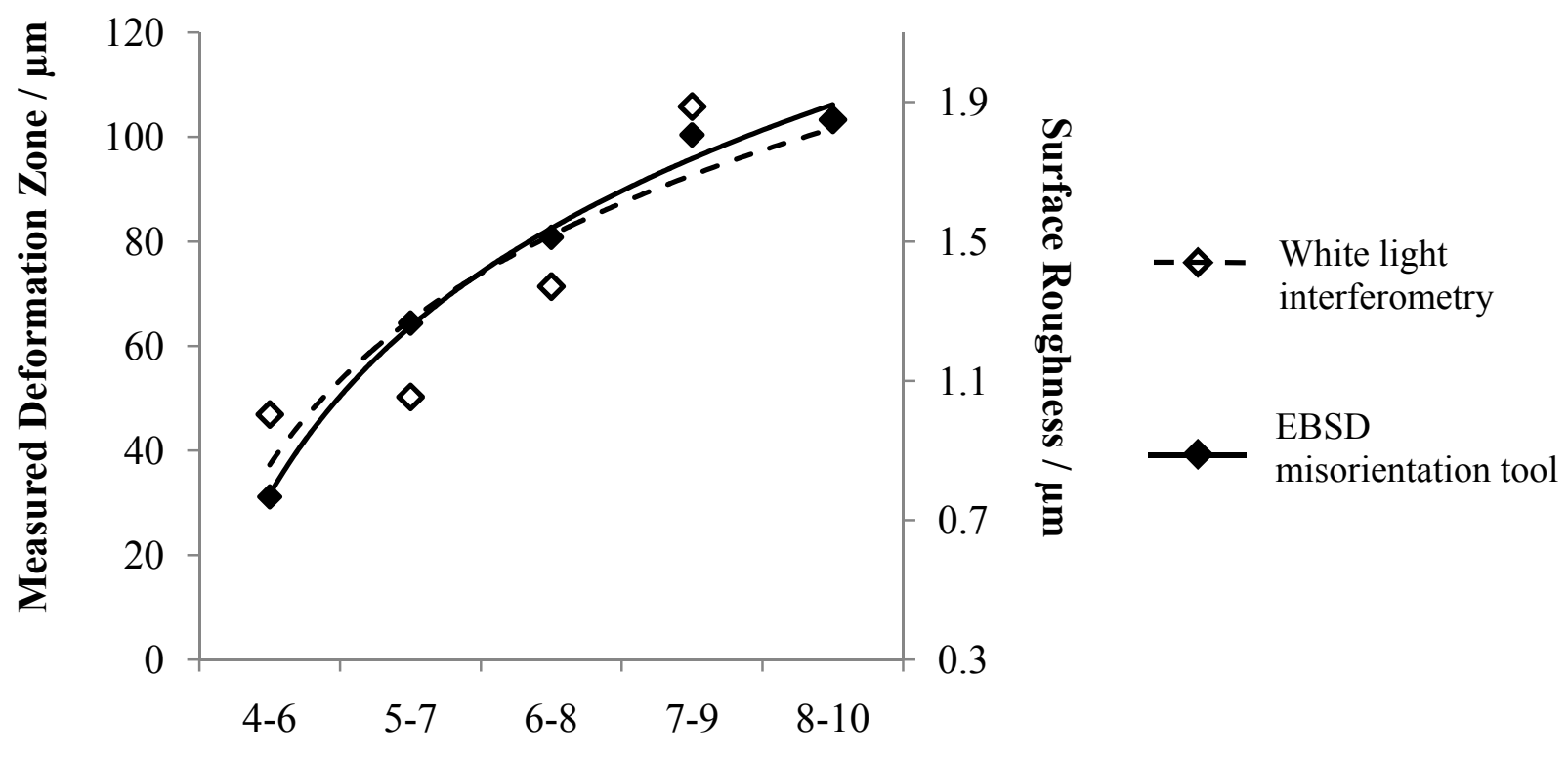

Shot Intensity / Almen 


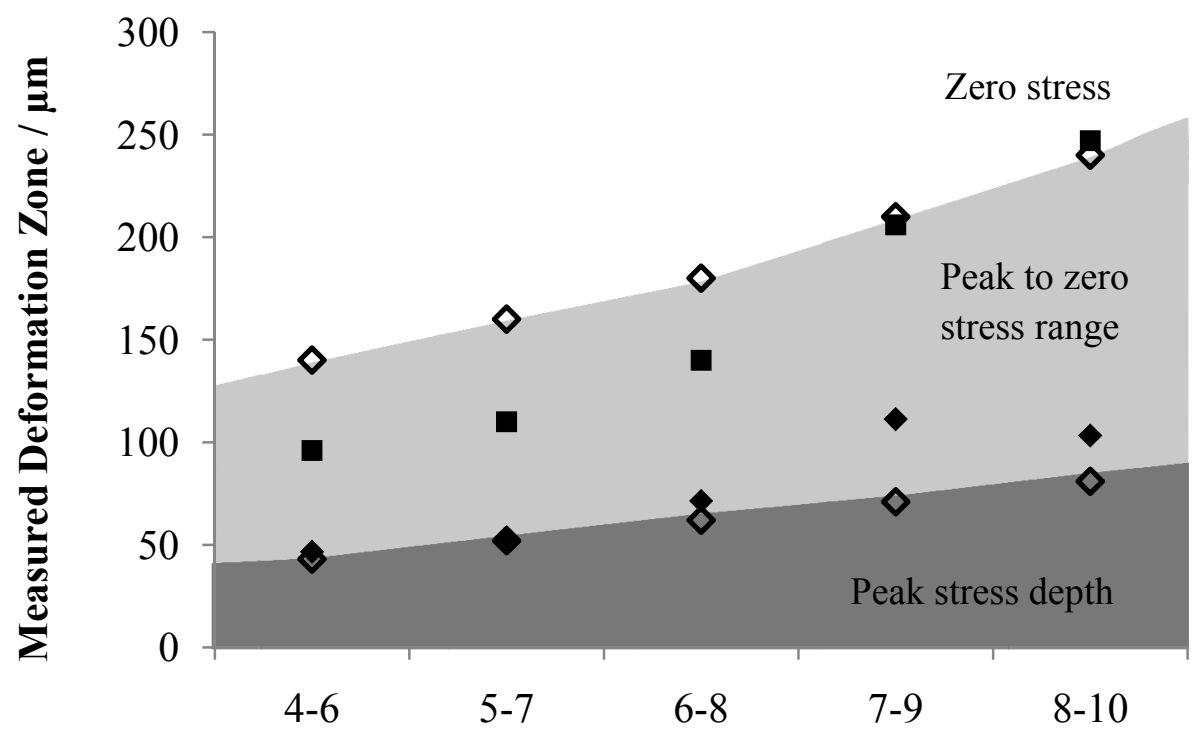

- EBSD tool

$\diamond$ Computer Simulation

- Hardness

Shot Intensity / Almen 


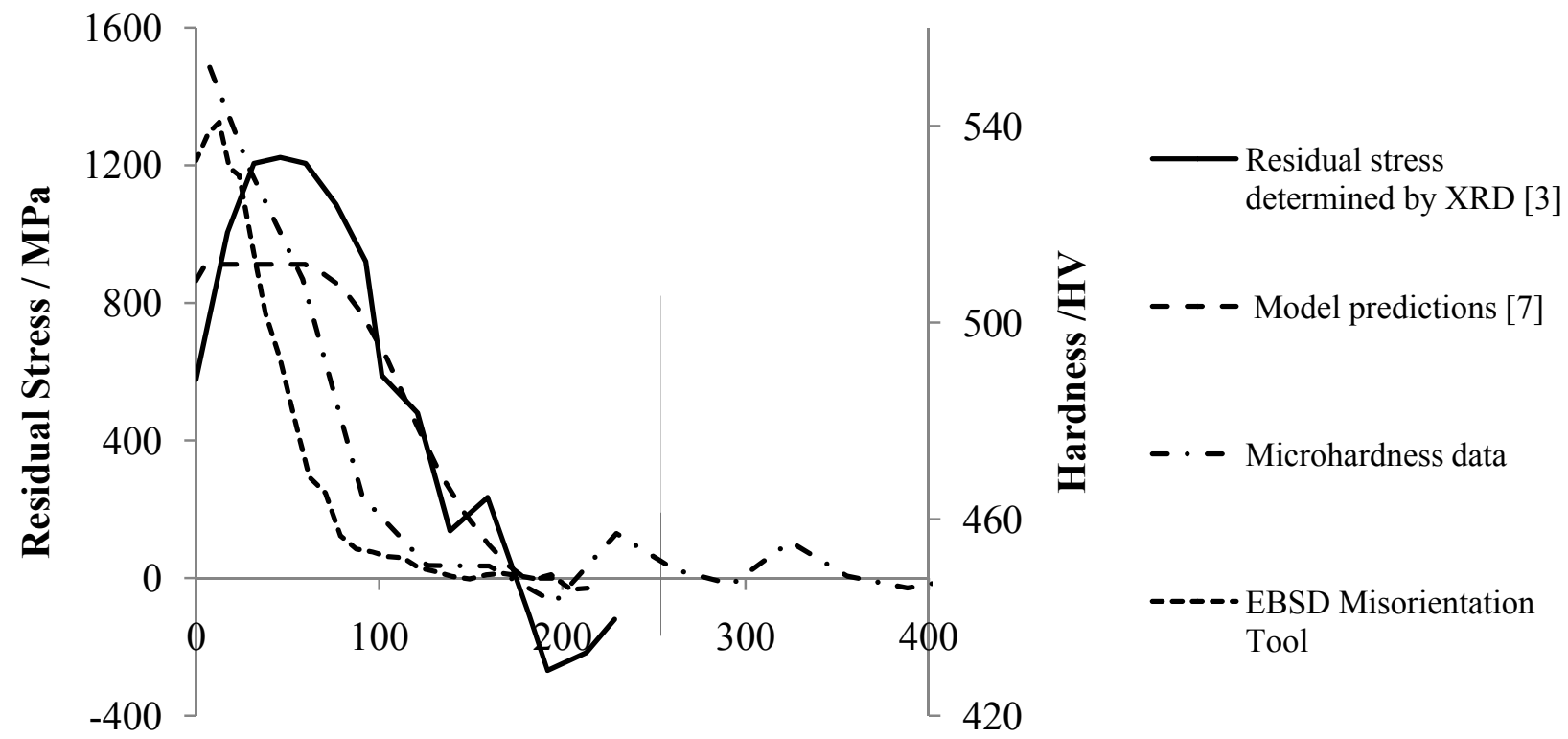

Distance from edge / $\mu \mathrm{m}$ 